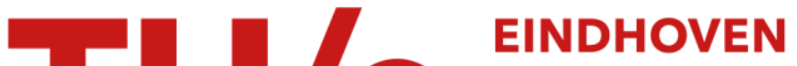 UNIVERSITY OF TECHNOLOGY
}

\section{All-optical label extractor/eraser for in-band labels and 160- $\mathrm{Gb} / \mathrm{s}$ payload based on microring resonators}

Citation for published version (APA):

Calabretta, N., Urban, P. J., Geuzebroek, D. H., Klein, E. J., Waardt, de, H., \& Dorren, H. J. S. (2009). All-optical label extractor/eraser for in-band labels and $160-\mathrm{Gb} / \mathrm{s}$ payload based on microring resonators. IEEE Photonics Technology Letters, 21(9), 560-562. https://doi.org/10.1109/LPT.2009.2014776

DOI:

10.1109/LPT.2009.2014776

Document status and date:

Published: 01/01/2009

\section{Document Version:}

Publisher's PDF, also known as Version of Record (includes final page, issue and volume numbers)

\section{Please check the document version of this publication:}

- A submitted manuscript is the version of the article upon submission and before peer-review. There can be important differences between the submitted version and the official published version of record. People interested in the research are advised to contact the author for the final version of the publication, or visit the $\mathrm{DOI}$ to the publisher's website.

- The final author version and the galley proof are versions of the publication after peer review.

- The final published version features the final layout of the paper including the volume, issue and page numbers.

Link to publication

\section{General rights}

Copyright and moral rights for the publications made accessible in the public portal are retained by the authors and/or other copyright owners and it is a condition of accessing publications that users recognise and abide by the legal requirements associated with these rights.

- Users may download and print one copy of any publication from the public portal for the purpose of private study or research.

- You may not further distribute the material or use it for any profit-making activity or commercial gain

- You may freely distribute the URL identifying the publication in the public portal.

If the publication is distributed under the terms of Article 25fa of the Dutch Copyright Act, indicated by the "Taverne" license above, please follow below link for the End User Agreement:

www.tue.nl/taverne

Take down policy

If you believe that this document breaches copyright please contact us at:

openaccess@tue.nl

providing details and we will investigate your claim. 


\title{
All-Optical Label Extractor/Eraser for In-Band Labels and 160-Gb/s Payload Based on Microring Resonators
}

\author{
N. Calabretta, P. J. Urban, D. H. Geuzebroek, E. J. Klein, H. de Waardt, and H. J. S. Dorren
}

\begin{abstract}
Photonic integration of an all-optical packet switch (AOPS) is a crucial issue since it leads to a great reduction of volume, power consumption, and costs. Recently, a $1 \times 4$ AOPS was successfully demonstrated by using an all-optical label extractor/eraser. The label extractor/eraser was implemented by means of fiber Bragg gratings and optical circulators that prevent the photonic integration of the AOPS. Here, we demonstrate a passive and asynchronous photonic integrated all-optical label extractor/eraser by using narrowband silicon-nitride add-drop ring-resonators. By exploiting the narrow bandwidth of the drop port and pass-through port error-free simultaneous separation/erasing of the in-band labels from the $160-\mathrm{Gb} / \mathrm{s}$ packet payload was demonstrated without noticeable pulse-shape distortions.
\end{abstract}

Index Terms-Optical processing, packet switching, ring resonators, wavelength filtering devices.

\section{INTRODUCTION}

A LL-OPTICAL packet switching based on all-optical signal processing is a promising technology to solve the mismatch between the fiber bandwidth and the router forwarding capacity [1], [2]. Moreover, it has been argued that all-optical technology can profit from the capability to integrate all the required switching functionalities in a photonic integrated chip to allow for a great reduction of volume, power consumption, and costs. It is then an essential issue to provide all-optical signal processing functionalities that are suitable for photonic integration.

Recently, an all-optical label extractor/eraser for in-band labeling addresses and $160-\mathrm{Gb} / \mathrm{s}$ data payload was successfully employed to demonstrate a $1 \times 4$ all-optical packet switch (AOPS) [3]. The AOPS schematic and the packet format are shown in Fig. 1. The optical address is encoded by combining the in-band labels (the wavelengths of the labels are located

Manuscript received October 24, 2008; revised December 19, 2008. First published February 13, 2009; current version published April 15, 2009. This work was supported by the Dutch Government, Freeband BB Photonics Project BSIK03025.

N. Calabretta, P. J. Urban, H. de Waardt, and H. J. S. Dorren are with COBRA Research Institute, Eindhoven University of Technology, $5600 \mathrm{MB}$, Eindhoven, The Netherlands (e-mail: n.calabretta@tue.nl; p.j.urban@tue.nl; h.d.waardt@tue.nl; h.j.s.dorren@tue.nl).

D. H. Geuzebroek is with LioniX B.V., 7500 AH, Enschede, The Netherlands (e-mail: d.h.geuzebroek@tue.nl).

E. J. Klein is with XiO Photonics, 7500 BG, Enschede, The Netherlands (e-mail: e.j.klein@xiophotonics.com).

Color versions of one or more of the figures in this letter are available online at http://ieeexplore.ieee.org.

Digital Object Identifier 10.1109/LPT.2009.2014776
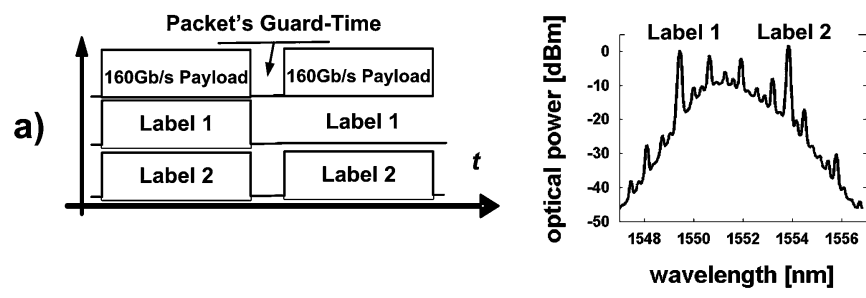

b)

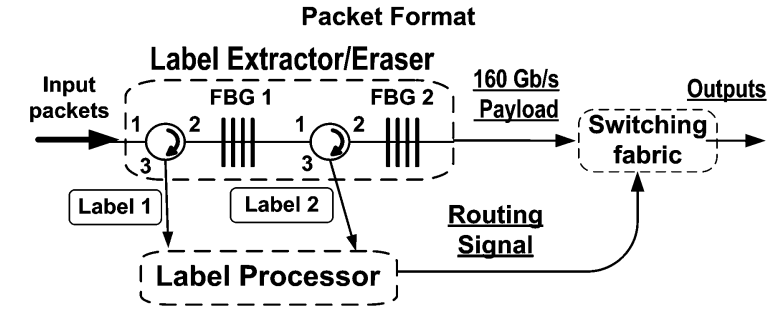

Fig. 1. (a) Packets format and in-band labeling technique. (b) AOPS configuration.

within the 20-dB bandwidth of the payload). The in-band labeling technique has the advantage that label extraction can be implemented by using passive optical bandpass filters centered at the labels wavelength and label erasing by using notch filters. In [3], the label extractor/eraser was implemented by exploiting the reflection and pass-through ports of two pigtailed fiber Bragg gratings (FBGs) centered at the label's wavelength and two optical circulators (see Fig. 1). Thus, the labels, reflected by the FBGs, are extracted via the optical circulators, while the data payload passes through the FBGs and is fed into the switching fabric. The extracted labels are optically processed by the label processor, which produces an optical routing signal driving the switching fabric.

Despite the successful demonstration of the AOPS and the potential integration of the label processor and switching fabric [3], photonic integration of the entire AOPS is prevented by the integration of the label extractor/eraser. Moreover, the broad bandwidth of the FBGs caused a splicing and distortion of the spectrum of the payload which resulted in a pulse broadening of the $160-\mathrm{Gb} / \mathrm{s}$ payload. This leads to a closed eye and, therefore, to an extra power penalty. The pulse distortion can be practically avoided by using optical bandpass filters with narrow bandwidth and optical notch filters with narrow stopband and flat all-pass band.

In this work, we demonstrate a label extractor/eraser for in-band labeling addresses and $160-\mathrm{Gb} / \mathrm{s}$ payload by using an integrated microring resonator with pass-through and drop port. By exploiting the narrow bandwidth of the drop port and the 


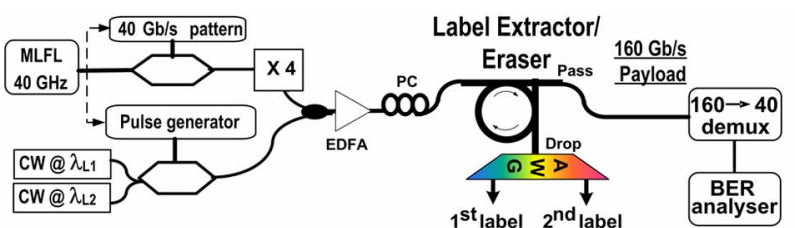

a)

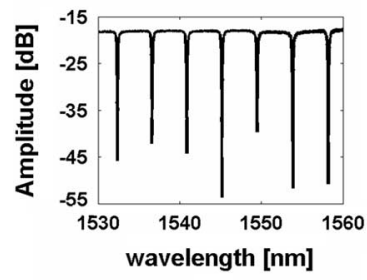

b)

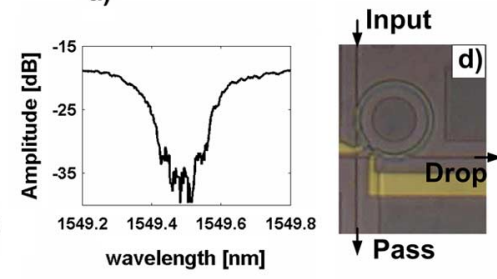

c)
Fig. 2. (a) Experimental setup. (b) Transfer function of the pass-through. (c) Magnification of one of the stopbands. (d) Scanning electron micrograph of the microring resonator employed in the experiments.

narrow bandwidth and flat all-pass band of the pass-through port, simultaneous error-free label extraction and label erasing has been performed without noticeable pulse distortion.

\section{EXPERIMENTS AND RESULTS}

The experimental setup employed to demonstrate the microring-based label extractor/eraser is shown in Fig. 2. The packet format is the same as the one shown in Fig. 1. Packet payload is generated by time-quadrupling a $40-\mathrm{Gb} / \mathrm{s}$ data stream consisting of 256 predefined return-to-zero bits $\left(\lambda_{p}=1551.6 \mathrm{~nm}\right)$ into a $160-\mathrm{Gb} / \mathrm{s}$ data stream using a passive pulse interleaver. Each pulse has duration of 1.5 ps making the 20-dB bandwidth of the payload to be $5 \mathrm{~nm}$. The resulting packet payload consists of a 5.6-ns data burst. The guard-time between the packets is $800 \mathrm{ps}$. We employ in-band labeling; the packet address information is encoded with continuous-wave (CW) signals at wavelengths within the 5-nm payload bandwidth. Each label can have a binary value: "0" means no signal at the label wavelength, "1" means an optical signal at the label wavelength. The duration of the label equals the duration of the payload. We encode the addresses by using two in-band labels at $\lambda_{L 1}=1549.45 \mathrm{~nm}$ and $\lambda_{L 2}=1553.85 \mathrm{~nm}$. Note that the two CW signals are modulated by one single amplitude modulator driven by a low-speed pattern generator.

The label extractor/eraser consists of pigtailed vertically coupled microring resonators fabricated in the $\mathrm{Si}_{3} \mathrm{~N}_{4}-\mathrm{SiO}_{2}$ materials system [4] (high contrast materials system, $\Delta n \approx 0.55$ ), with a pass-through port and a drop port as shown in Fig. 2(a). The transfer function of the pass-through port is reported in Fig. 2(b). The free-spectral range (FSR) of the periodic stopbands is $4.4 \mathrm{~nm}$. A magnification of one of the stopbands is shown in Fig. 2(c). The measured $-3-\mathrm{dB}$ bandwidth was $0.16 \mathrm{~nm}$ and the flatness of the passband was $\pm 0.4 \mathrm{~dB}$. The total loss of the device is $20 \mathrm{~dB}$, of which $16 \mathrm{~dB}$ are coupling losses and $4 \mathrm{~dB}$ are waveguide losses in the ring. The optical packets are amplified and processed by the label extractor/eraser. A polarization controller controls the input polarization to the microring. The stopbands at multiple FSR are designed to be at the wavelengths matching the labels' wavelengths. Therefore,
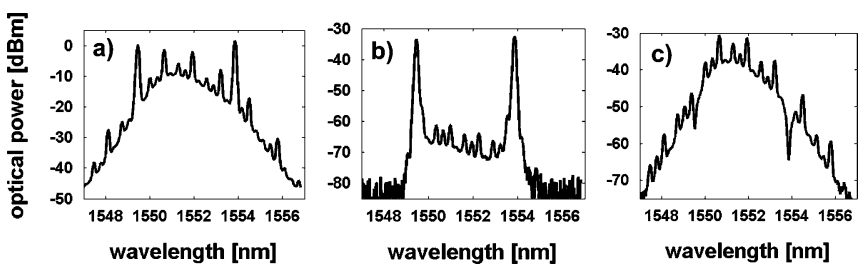

Fig. 3. Measured optical spectra. (a) Optical packets at the input of the label extractor. (b) Output of the drop port showing the optical spectra of the two labels. (c) Output of the pass-through port showing the optical spectrum of the $160-\mathrm{Gb} / \mathrm{s}$ payload.

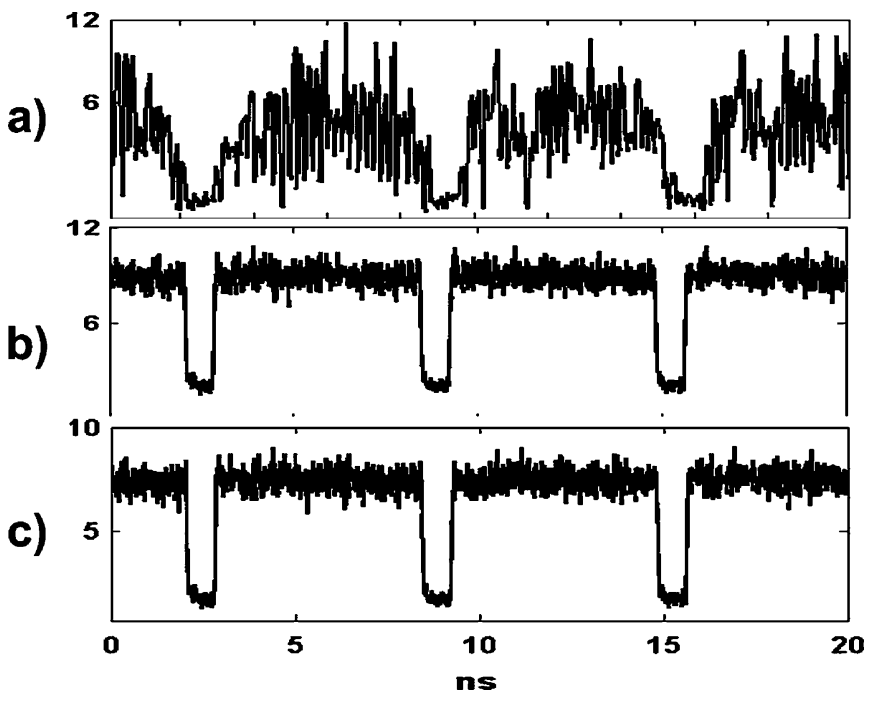

Fig. 4. (a) A 160-Gb/s payload after the label extractor. (b) and (c) Extracted Label 1 and Label 2. The vertical scale is $\mathrm{mV} / \mathrm{div}$.

the labels' wavelengths are filter out at the drop-port, while the wavelength payload is output to the pass-through port. The two labels at wavelength $\lambda_{L 1}$ and $\lambda_{L 2}$ are output from the drop port and then separated by an arrayed waveguide grating (AWG) filter ready to be fed into the label processor. This is confirmed by spectral and time-domain measurements. In Fig. 3, the optical spectra measurements with resolution bandwidth of $0.06 \mathrm{~nm}$ at the drop and pass-through ports are reported. The optical spectrum of the input packet before the label extractor is shown in Fig. 3(a). The optical spectrum at the output of the drop port and the pass-through output port are reported in Fig. 3(b) and (c). More than $25 \mathrm{~dB}$ of separation/erasing between the labels and the optical payload were measured.

We also report in Fig. 4(a)-(c) the time-domain traces of the $160-\mathrm{Gb} / \mathrm{s}$ payload and the extracted label traces (after the AWG) recorded at the pass-trough port and drop port, respectively. Note that the two labels have the same pattern, because we employed a single amplitude modulator driven by a pattern generator to modulate the two $\mathrm{CW}$ signals at $\lambda_{L 1}$ and $\lambda_{L 2}$. The labels present no shape distortion and no visible crosstalk due to the payload.

The eye diagrams of the original input $160-\mathrm{Gb} / \mathrm{s}$ data payload and of the $160-\mathrm{Gb} / \mathrm{s}$ payload after the label extractor/eraser are reported in Fig. 5(a)-(c). An optical sample oscilloscope with $700 \mathrm{GHz}$ of bandwidth was employed to record the eye diagrams of the $160-\mathrm{Gb} / \mathrm{s}$ pulses. Very small degradation and 


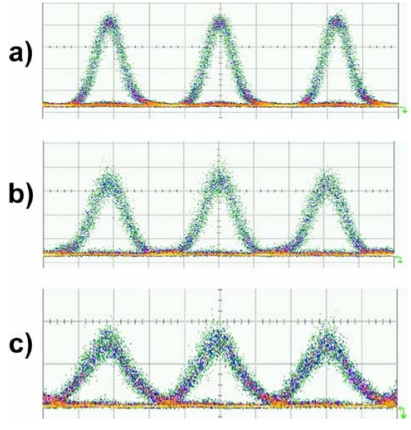

Fig. 5. (a) Eye diagram of the input $160-\mathrm{Gb} / \mathrm{s}$ payload. (b) Eye diagram of the $160-\mathrm{Gb} / \mathrm{s}$ payload after the label extractor/eraser. (c) Eye diagram of the $160-\mathrm{Gb} / \mathrm{s}$ payload after the label extractor/eraser employed in [3]. The time scale is $2 \mathrm{ps} / \mathrm{div}$.

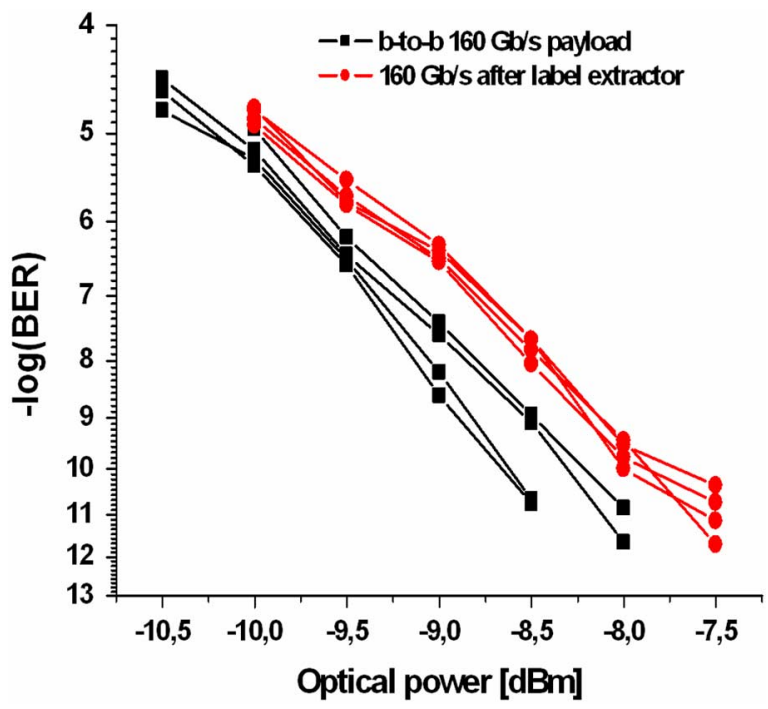

Fig. 6. BER measurements before and after the label extractor/eraser.

broadening of the pulses is observed after the label extraction. The measured pulsewidth broadening was $0.4 \mathrm{ps}$. The measured root-mean-square (rms) time jitter was $212 \mathrm{fs}$ for the pulses after the label extractor/eraser, which results in an increase of $40 \mathrm{fs}$ compared to the $173 \mathrm{fs}$ of the input $160-\mathrm{Gb} / \mathrm{s}$ payload pulses. For comparison, we also reported in Fig. 5(c) the eye diagram of the $160-\mathrm{Gb} / \mathrm{s}$ payload after the label extraction implemented by using the FBGs as in [3]. A much larger pulse broadening can be observed caused by the broad bandwidth of the FBGs ( $-3-\mathrm{dB}$ bandwidth of 0.42 and $0.1 \mathrm{~nm}$ for FBG1 and FBG 2, respectively) compared to the bandwidth of the microring add-drop resonator.

To quantify the performance of the label extractor/eraser, biterror-rate (BER) measurements are reported in Fig. 6. The BER measurements were performed in a static operation by time-quadrupling $40-\mathrm{Gb} / \mathrm{s}$ pseudorandom binary sequence $2^{31}-1$ data payload. The resulting $160-\mathrm{Gb} / \mathrm{s}$ data payload after the label extractor/eraser is amplified and time-demultiplexed from 160 to $40 \mathrm{~Gb} / \mathrm{s}$ by using an electrically clocked electroabsorption modulator that creates a 5-ps switching window with a periodicity of $25 \mathrm{ps}$. The resulting $40-\mathrm{Gb} / \mathrm{s}$ data is then detected by a
40-Gb/s detector and analyzed by using a BER tester. As reference, we report the BER curve of the back-to-back $160-\mathrm{Gb} / \mathrm{s}$ payload. The BER curve of the $160-\mathrm{Gb} / \mathrm{s}$ payload after the label extraction/eraser shows error-free operation with limited power penalty of around $0.5 \mathrm{~dB}$. The power penalty can be ascribed to the additional amplified spontaneous emission noise introduced by the amplification stage required to compensate the total loss of the label extractor/extractor.

\section{CONCLUSION}

We have demonstrated error-free operation of a photonic integrated all-optical label extractor/eraser for in-band labeling addresses by using a passive silicon-nitride microring add-drop resonator. The in-band labels and the $160-\mathrm{Gb} / \mathrm{s}$ payload of the optical packets were successfully separated to the drop port and pass-through port, respectively. Due to the narrow stopband and flatness of the passband of the pass-through port of the microring, almost no distortion is experienced by $160-\mathrm{Gb} / \mathrm{s}$ payload spectrum. As a result, the $160-\mathrm{Gb} / \mathrm{s}$ payload pulses exhibit very limited broadening, in contrast with the visible broadening experienced by the payload pulses by using FBGs with broader stopband [3]. This resulted in a low power penalty of $0.5 \mathrm{~dB}$. The negligible spectral distortion of the payload due to the utilization of microring with a narrow stopband is also very important in the perspective to operate the label extractor/eraser with a larger number of labels. We are currently designing for the realization of a microring resonator capable of extracting/erasing a larger number of in-band labels. Moreover, novel design will benefit from the achievement in technology to realize polarization independent and low insertion loss microring add-drop resonator as demonstrated in [5], [6]. Finally, it is worth to note that since the previous implementation of the label extractor/eraser employed in [3] was not suitable for photonic integration, the photonic integration of the AOPS node was prevented. This work demonstrates the feasibility for photonic integration of the label extractor/eraser, which may allow for photonic integration of the entire AOPS configuration.

\section{REFERENCES}

[1] D. J. Blumenthal, B.-E. Olsson, G. Rossi, T. E. Dimmick, L. Rau, M. Masanovic, O. Lavrova, R. Doshi, O. Jerphagnon, J. E. Bowers, V. Kaman, L. A. Coldren, and J. Barton, "All-optical label swapping networks and technologies," J. Lightw. Technol., vol. 18, no. 12, pp. 2058-2075, Dec. 2000.

[2] J. Herrera et al., "160 Gb/s all-optical packet switched network operation over $110 \mathrm{~km}$ of field installed fiber," in Proc. OFC 2007, Anaheim, CA, 2007, Paper PDP4.

[3] N. Calabretta, H. D. Jung, J. Herrera, E. Tangdiongga, A. M. J. Koonen, and H. J. S. Dorren, " $1 \times 4$ all-optical packet switch at $160 \mathrm{~Gb} / \mathrm{s} \mathrm{em-}$ ploying optical processing of scalable in-band address labels," in Proc. OFC 2008, San Diego, CA, 2008, Paper PDP 33.

[4] E. J. Klein et al., "Densely integrated microring resonator based photonic devices for use in access networks," Opt. Express, vol. 15, pp. 10346-10355, 2007.

[5] F. Morichetti, A. Melloni, M. Martinelli, R. G. Heideman, A. Leinse, D. H. Geuzebroek, and A. Borreman, "Box-shaped dielectric waveguides: A new concept in integrated optics?," J. Lightw. Technol., vol. 25, no. 9, pp. 2579-2589, Sep. 2007.

[6] W. Hoving, R. Heideman, D. Geuzebroek, A. Leinse, E. Klein, and R. Dekker, "Low loss, high contrast planar optical waveguides based on low-cost CMOS compatible LPCVD processing," Proc. SPIE, vol. 6996, p. 699612, 2008. 